\title{
A Dentigereus Cyst Containing Displaced Tooth in the Maxillary Sinus
}

Sahin $\mathbf{C}^{1 *}$, Uzun $\mathrm{A}^{2}$ and Parlak $\mathrm{S}^{2}$

${ }^{1}$ Sakarya government hospital ENT Clinic, Sakarya, Turkey

${ }^{2}$ Hasvak Hospital Ankara, Turkey

\begin{abstract}
Ectopic eruption of tooth has been reported in the nasal septum, chin, palate, coronoid process and maxillary sinus in the literature. A tooth may erupt maxillary sinus and present with chronic sinusitis, mucosele and cyst formation. Obstruction the osteomeatal complex, formation of cyst in the maxillary sinus, obstruction of nasolacrimal canal leading to epiphora may occur because of the anatomic variation. There may be sinonasal symptoms of sinusitis, epiphora and pain. The diagnosis of this condition can be made radiologically. If it is symptomathic treatment of ectopic maxillary tooth with dentigerous cyst is surgical removal via a Caldwell-Luc procedure. Herein we present an original image of a dentigerous cyst containing premolar tooth in the maxillary sinus.
\end{abstract}

Keywords: Tooth eruption; Maxillary sinus; Dentigerous cyst

\section{Case Report}

A 43-year-old man was presented with the complaints of recurrent pain and pressure in right maxillary sinus region. He had a history of recurrent sinusitis of 5 years duration. The symptoms did not resolve despite several courses of medical therapy. The past medical history was unremarkable.

Findings of anterior rhinoscopy examination were normal. In the endoscopic examination mucoid secretion was seen in right middle meatus. External examination of teeth revealed normal findings. There was no history of tooth extraction. There was no swelling in maxillary region. Intraoral examination was normal. Ocular examination was normal. Findings of blood and serum biochemistry were within normal limits. A plain computed tomography (CT) scan of the paranasal sinuses was done by taking 3-mm coronal slices. CT examination of the paranasal sinuses revealed a dentigerous cyst containing first premolar tooth in the maxillary sinus. The cyst was seen to expand in the alveolar process of the maxillary bone (Figure 1). The patient did not accept the recommended surgical treatment.

\section{Discussion}

Maxillary dentigerous cysts are common disorders of the maxillary sinus. Most frequently, the cysts are incidental findings on radiographs. Etiology of the disease is not clear; inflammation, infection, allergy, odontogenic and rhinologic factors are believed to play role.

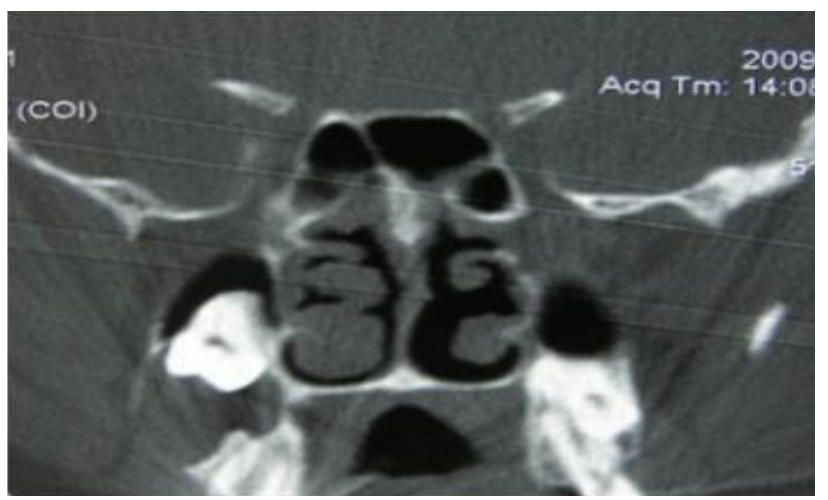

Figure 1: A computed tomography (CT) scan of the paranasal sinuses revealed a dentigerous cyst containing first premolar tooth in maxillary sinus. The cyst made expansion in alveolar process of maxillary bone.
The etiology of ectopic tooth eruption is still unclear. During development any abnormal tissue interaction between these cells may result in ectopic tooth development and eruption to different places may occur. The tooth can migrate to several locations including the maxillary sinus, nose, and infraorbital area [1]. Tooth development into the maxillary sinus is rare [2]. This eruption may lead to local sinonasal sign and symptoms attributed to recurrent sinusitis. Obstruction the osteomeatal complex, formation of cyst in the maxillary sinus, obstruction of nasolacrimal canal leading to epiphora may occur because of the anatomic variation [3,4]. Approximately 50 cases of a tooth in the nasal cavity have been reported in the literature [5].

The diagnosis of this condition can be made radiologically. Radiographs of the maxillary sinuses show of the highly radiopaque tooth and related situations. In the present case, the condition was detected using paranasal sinus tomography.

Patients with an ectopic tooth eruption into the maxillary sinus can remain asymptomatic. In the literature local sinonasal sign and symptoms like nasal obstruction, facial fullness, headache and epiphora were reported [6]. In the present case the patient complained of facial fullness and headache.

If it is symptomathic treatment of ectopic maxillary tooth with dentigerous cyst is surgical removal via a Caldwell-Luc procedure. Removal of the all antral tissue is crucial and assessment of the all resected soft tissue histologically is also crucial. This is important as certain antral diseases like odontogenic keratosis may co-exist with an ectopic premolar. Displacement of teeth by expansion of any dental pathology like odontogenic keratosis may result ectopic eruption of such teeth. If there is no assosiated unusual pathology, surgery can provide cure. In our case the patient did not accept recommended surgery. We cannot discuss about the treatment because of the reason but we present intense image of a cyst containing tooth. This reminds

${ }^{*}$ Corresponding author: Dr. Caner Sahin, Sakarya government hospital ENT Clinic, Sakarya, Turkey, Tel: +90 5345116076; E-mail: drcaner2001@gmail.com

Received February 12, 2014; Accepted February 22, 2014; Published February 24, 2014

Citation: Sahin C, Uzun A, Parlak S (2014) A Dentigereus Cyst Containing Displaced Tooth in the Maxillary Sinus. Dentistry 4: 211. doi:10.4172/21611122.1000211

Copyright: (C) 2014 Sahin C, et al. This is an open-access article distributed under the terms of the Creative Commons Attribution License, which permits unrestricted use, distribution, and reproduction in any medium, provided the original author and source are credited. 
Citation: Sahin C, Uzun A, Parlak S (2014) A Dentigereus Cyst Containing Displaced Tooth in the Maxillary Sinus. Dentistry 4: 211. doi:10.4172/21611122.1000211

us to further evaluate patients of chronic sinusitis to make appropriate diagnosis.

\section{References}

1. Baykul T, Doru $\mathrm{H}$, yasan $\mathrm{H}$, Aksoy M (2006) Clinical impact of ectopic teeth in the maxillary sinus. Auris Nasus Larynx 33: 277-281.

2. Dagıstanlı S, Cakur B, Goregen M (2007)A dentigerous cyst containing an ectopic canine tooth below the floor of the maxillary sinus. J Oral Sci 49: 249-252.

3. Litvin M, Caprice D, Infranco L (2008) Dentigerous cyst of the maxilla with impacted tooth displaced into orbital rim and floor. Ear Nose Throat J 87: 160-162.
4. Ray B, Bandyopadhyay SN, Das D, Adhikary B (2009) A rare cause of nasolacrimal duct obstruction: Dentigerous cyst in the maxillary sinus. Indian $J$ of Ophthalmology 57: 465-467.

5. Buyukkurt MC, Omezli C, Miloglu O (2010) Dentigerous cyst associated with an ectopic tooth in the maxillary sinus: a report of 3 cases and review of the literature. Oral Surg Oral Med Oral Pathol Oral Radiol Endod 109: 67-71.

6. Shana Y, Kaushik S, Sighn P (2003) A case of large dentigerous cyst containing tooth in the maxillary antrum. Indian J of Otolaryngology Head Neck Surg 55: 199-201. 